\title{
ARTIFICIAL FINGER JOINTS IN RHEUMATOID ARTHRITIS \\ I. DEVELOPMENT AND EXPERIMENTAL ASSESSMENT
}

\author{
BY \\ J. S. CALNAN AND N. D. REIS* \\ From the Unit for Experimental Plastic and Reconstructive Surgery, Royal Postgraduate Medical School, \\ University of London
}

Present-day treatment of rheumatoid arthritis has not yet reached the stage at which the natural progression of the disease can be halted. This is made patently clear by the large numbers of crippled hands seen in any rheumatology clinic. There is some evidence that early synovectomy will slow down the progressive destruction of diseased joints so often observed during the period of review through the years of any one patient. Be that as it may, those hands which are already the seat of advanced rheumatoid disease pose a complex problem of rehabilitation, which in many cases cannot be complete until a satisfactory joint prosthesis becomes available for the destroyed metacarpophalangeal and interphalangeal joints. The following disquisition presents the case for development of a new joint prosthesis.

\section{The Argument for Prosthetic Finger Joints}

\section{(1) Patho-Anatomical Basis}

The rheumatoid process commences in the synovial membrane as a chronic inflammatory hyperplasia. The normal synovial membrane is a fine structure a few cell layers thick supported variously by areolar, fibrous, or fatty tissue according to whether it lies over potential space, capsule and ligament, or fat pad respectively. The rheumatoid process changes this into a thick, velvety, friable, and highly vascular structure. Encroaching as a pannus on the articular surfaces of a joint, it erodes the articular cartilage and finally the bone. Where it is in contact with capsule or ligament these structures too, although more resistant than cartilage or bone, in turn become the seat of rheumatoid disease. The destruction of the articular surfaces of a joint further results in slackening of the supporting soft tissues. The slack capsule and ligaments are

* Sembal Research Fellow. elongated further by the pull of the dominant muscle group acting on that joint, during the phase in which they themselves are affected by the disease. At this stage the joint subluxates or dislocates. As the disease progresses to its final reparative or fibrous stage and becomes "burnt out", fibrosis of the areas of rheumatoid lesions fixes the joint in its dislocated position.

Thus in the hand at the metacarpo-phalangeal joints, the dominant muscles are the flexors, namely the small intrinsic muscles as primary movers (frequently themselves in a state of contracture) and the powerful superficial and deep long flexors of the fingers as secondary movers. The final result of joint destruction is palmar dislocation of the bases of the proximal phalanges. The combination of shortening due to destruction of the bone ends, palmar dislocation of the proximal phalanges, and joint instability throws off balance this complex muscle mechanism controlling positions of the fingers, as well as weakening the grip because the long flexors can no longer take up this additional slack in the tendon. A similar development may occur also in the thumb.

Simultaneously, or independently, another pathological process, that of ulnar deviation of the fingers, takes place. Normally the action of the dominant flexors exerts a slight ulnar deviating strain owing to the shape of the articular surfaces of the metacarpophalangeal joints (Smith and Kaplan, 1967), so that in the normal clenched hand the fingers are in slight ulnar deviation. The latter movement is limited by the radial collateral ligaments, and by the locking action of the fifth finger. In rheumatoid arthritis, on the other hand, the radial collateral ligaments of the metacarpophalangeal joints may become lax and elongated and therefore unable to counter the normal ulnar strain in flexion, and in addition the intrinsic adductor action of the fifth finger is also weakened. The result is progressive ulnar deviation 
at the metacarpophalangeal joint: the long extensor tendons can then slip off the heads of the metacarpals into the groove on the ulnar side, and in this new position now accentuate and perpetuate the ulnar drift (Smith and Kaplan, 1967).

The same disease process in the interphalangeal joints rarely leads to dislocation, presumably because muscle balance here is less complex. Nevertheless, the proximal interphalangeal joints may become completely stiff through bony ankylosis or advanced boutonnière deformity, the latter most commonly caused by erosion and elongation of the central slip of the extensor tendon. In the "swan neck" deformity, the proximal interphalangeal joints cannot be flexed when the metacarpophalangeal joint is extended. Such disability is due, however, to intrinsic muscle contracture and not to disease of the IP joint. Interphalangeal joint function may also be limited by simple fibrosis of the periarticular tissues causing stiffness, or by instability due to destruction of the collateral ligaments or gross destruction of the articular bone ends.

\section{(2) Evidence from Previous Work}

The earliest attempts to treat dislocation of the metacarpophalangeal joint were by arthroplasty without the use of any prosthesis (Vainio, 1967; Fowler and Riordan, 1958). When ulnar deviation was also present this was corrected by incising the extensor hood on the ulnar side and reefing it on the radial side, thereby relocating the long extensor tendon over the metacarpal head. These procedures met with some success but the results were rarely good because they depended on repair of soft tissues alone, and these soft tissues were often themselves the seat of rheumatoid disease, or became so later.

Stiffness in a position of poor function or instability of the interphalangeal joints was treated by arthrodesis of the joint in slight flexion. Arthrodesis was performed only because there was no choice, and fixation of joints in a hand already deformed and poorly mobile was correctly regarded as unsatisfactory.

It became clear that some form of artificial joint, which would not itself be affected by disease, was required to stabilize such destroyed joints. The pioneer in this field was Flatt (1961) who designed a light-weight Vitallium hinge joint in five sizes for both metacarpophalangeal and interphalangeal joints. His joint was in two sections and the stem of each section had double prongs. Each section was driven into the marrow cavity of the cut bone ends: the prongs impinged on the cortex of the bone and from being compressed towards one another gained purchase on the bone. When correctly positioned the two halves were then connected by a bolt which was seated permanently by crimping. Wedges of bone on the palmar side of the adjacent shafts were pared off to allow for a greater range of flexion at the joint. Flatt had improved on an earlier metal hinged joint (Brannon and Klein, 1959), in which a single prong was inserted into each shaft of the metacarpal and phalanx before being united as a conventional hinge. He had found that a single stem rotated within the marrow cavity, and designed his double prong to prevent this. Flatt reported considerable success with proximal interphalangeal joints, and qualified success with metacarpophalangeal joints when used for metacarpophalangeal joint dislocation. He also reported good results in pure ulnar deviation, using prosthetic joints as corrective posts for the fifth and middle fingers. These prostheses are expensive and occasionally do not grip the bone sufficiently and so become rotated. Moreover, at the metacarpophalangeal joint, they have the further disadvantage of allowing only pure flexion-extension movement, preventing the fine functions of abduction, adduction, and rotation, and thus limiting these finer functions at that site.

Thompson designed a hinge joint, Bateman a plateau for phalangeal head replacement, and Street a plateau for the base of the proximal phalanx, but there has been no publication of their use at the time of writing (see London Splint Co. Catalog, 1964). McKee and Watson-Farrar (1966) designed and used a hinge joint but found the results disappointing in hands affected by rheumatoid arthritis, and Bäckdahl (1966) has used a "Teflon" joint similar in design to that of one of our early prototypes.

\section{(3) Theoretical Form of an Ideal Prosthesis}

Stimulated by Flatt's work, we have tried to solve some of the problems presented by hinged metal joints. We believe an ideal prosthesis should have the following qualities:

(a) Stability;

(b) Adequate range of movement for that joint being replaced;

(c) Hard wearing;

(d) Solid anchorage;

(e) Cheapness;

$(f)$ No tissue reaction to material used.

Flatt's prosthesis answers well to requirements $a$, $c$, and $f$, but not to $d$ and $e$, and $b$ was poor at the metacarpophalangeal joint. 
The requirement of cheapness is met only by using some kind of plastic, and for adequate lateral movement at the metacarpophalangeal joint a fresh design was imperative. For solid anchorage of the joint to bone a different method of fixation had to be sought.

\section{Preliminary Development}

\section{(1) Choice of Polypropylene}

Polyvinylchloride although flexible is not as strong as polypropylene, and polytetrafluo-ethylene has such a high melt viscosity that it cannot be worked by ordinary extrusion methods. Nylon is strong but imbibes water with alteration of its properties. UF, PF, and ureaformaldehyde resins are stiff and brittle. The plastic that seemed to have all the required properties was polypropylene, a member of the polythene group of plastics but possessing different properties.

Polypropylene is the lightest of all plastics in sheet form. Its melting point is $165-175^{\circ} \mathrm{C}$. (higher than that of all polythenes) and it may be boiled or autoclaved without losing shape or strength. It also creeps less under load than the polythenes.

Its rigidity and hardness are such that it may be used for food-mixer parts or shoe heels. But above all its ability to be moulded as an integral hinge recommends it for joint prostheses (see later).

\section{(2) Stages in the Development of Polypropylene Joints}

Our first prototype was similar to Flatt's prosthesis (Fig. 1), being composed of two parts with square shafts; the articulation was by two flat surfaces cut back from the axis of the shaft and held together by a polypropylene bolt. The advantage of having the joint in two halves, which could be fitted together after seating in the bone, allows the length of the shaft introduced into the bone marrow to be limited only by the length of the cavity itself. The disadvantage lies in the necessity for perfect mutual alignment of the two halves in the bone prior to locking them together with the bolt.

The second prototype was similar in principle but utilized a joint similar to McKee's-namely two lateral eyes on the one side fitting onto one central eye on the other. Whereas in McKee's joint these were then secured by a through and through screw bolt, our plastic version left the central eye imperforate and supplied it with projections on either side which locked into the lateral eyes. This joint was found to be unstable to lateral strains

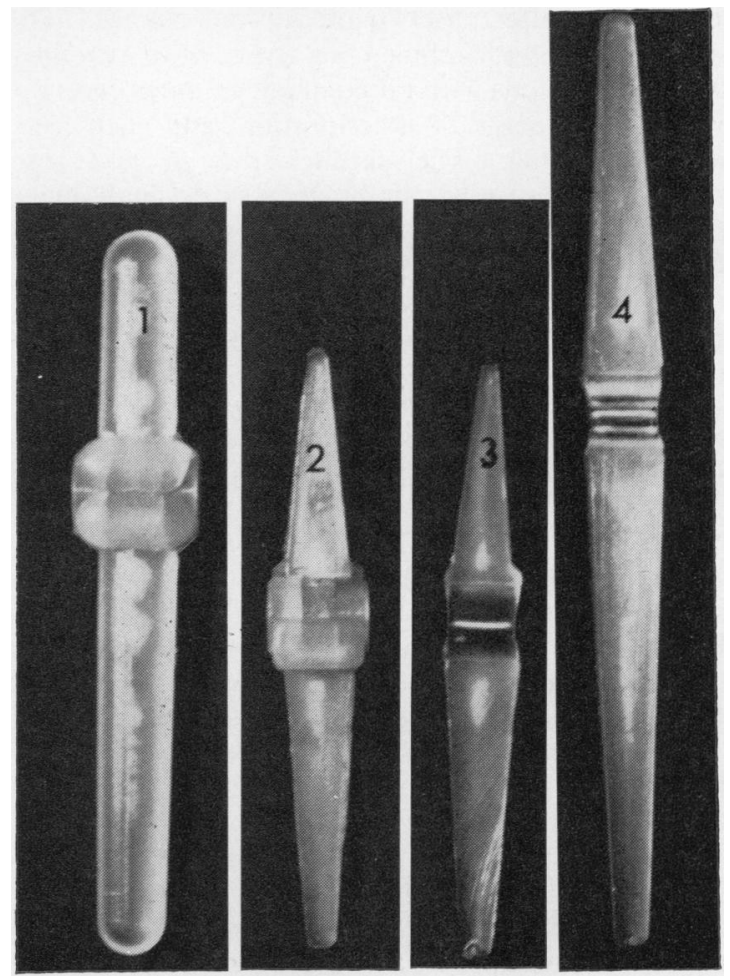

Fig. 1.-Types of plastic joints used:

(1) Early prototype of conventional hinge, the two shafts united by (2) Later type with lugs fitting into eyes of

(3) Single piece, integral hinge joint used in dogs and later in humans. (4) Larger integral hinge joint, suitable for humans.

when the central eye projections were short enough to allow easy manual assembly and disruption.

Both of the foregoing joints allowed movement in only one plane. Yet a satisfactory joint for the MC-P articulation should allow for some movement in a plane at right angles to flexion and extension, and ideally some rotation.

At this time we became interested in the principle of the integral hinge joint for which polypropylene is the ideal material. The simplicity of this single piece prosthesis commended itself. If the prosthesis is moulded as a single piece, shaft length is limited only by the space between the bone ends at time of its insertion. Furthermore the integral hinge, whilst being stable, is not entirely rigid, allowing a fraction of rotation and lateral movement, and may thus be sufficiently versatile to suit interphalangeal and metacarpophalangeal joints.

When properly designed and moulded such a hinge can withstand constant flexing for indefinitely long periods. On the flex testing apparatus used by Imperial Chemical Industries (Estevez, 1966), hinges have exceeded 23 million flexes without failure and 
ten million after autoclaving without change. On our own testing machine (Fig. 2) we have exceeded 2 million flexions with hinges made in our workshop without any signs of deterioration, and such tests are continuing. The tensile strength and tear resistance of a well-made hinge is surprisingly high. Our experimental observation on dogs (see later) have shown that a new fibrous and strong capsule reforms around the joint after prosthetic arthroplasty, and this capsular support ensures stability of the integral hinge against unusual trauma.

The polypropylene integral hinge is the very thin web of material connecting the two component shafts, and is by far the thinnest section of the assembly (0.01 in. to $0.0015 \mathrm{in}$.). The overall size of the article and the length of the hinge do not affect the dimensions shown in Fig. 1 but the radius of 0.03 in. to 0.04 in. is important and critical. Flexing this web induces molecular orientation. Unorientated molecules are randomly placed in the plastic and the strength of the chemical chain strength is distributed in all directions. Orientation by flexing in a direction normal to the hinge length aligns the polymer molecules in that direction thereby producing an immense increase in strength. This orientation is initiated during moulding and completed by the flexion movement. When orientated, the molecules lie at right angles to the axis of the hinge.

\section{(3) Securing of Rigid Anchorage}

Whatever the prosthesis used, firm attachment of its shafts to bone is essential, for otherwise it may rotate and move within the bone marrow cavity and this may give rise to pain.

The problem of anchorage was considered from two apsects:

(a) The shape of the prosthetic stem;

(b) Methods of fixation of the stem within the marrow cavities.

In order to avoid rotation of the prosthesis, we $\stackrel{\mathbb{Q}}{\varrho}$ made the cross-section of each stem discoid, and later rectangular.

But it soon became clear that, whatever the shape of the prosthetic stem, no design could achieve rigid $\vec{\omega}$ fixation within the bone, even though the medullary cavity was carefully reamed out to shape with fine $\overline{0}$ drills and rasps. However perfect the resultant fit $N$ of the cavity to the prosthetic stem, there always $\dot{\omega}$ remained some degree of movement between stem $N$ and marrow cavity. We discovered later that this method of fixation, which depended on exact work- 은 manship, inevitably resulted in an unstable joint because of the small free movements between the joint shafts and the marrow cavities.

It was therefore essential to cement the shafts to $\vec{\bullet}$ bone. Cold-cure acrylic used in dentistry has for $\infty$ some years been adapted to orthopaedic work (Charnley, 1960; McKee and Watson-Farrar, 1966), and it was decided to use this cold-cure resin of methylmethacrylate in our work.

This plastic resin has certain advantageous properties. The powder supplied is a polymer, and the liquid is a monomer of the methyl ester of methacrylic acid, with the basic monomeric formula:

$\mathrm{CH}_{2}: \mathrm{C}\left(\mathrm{CH}_{3}\right)$. COO. $\mathrm{CH}_{3}$

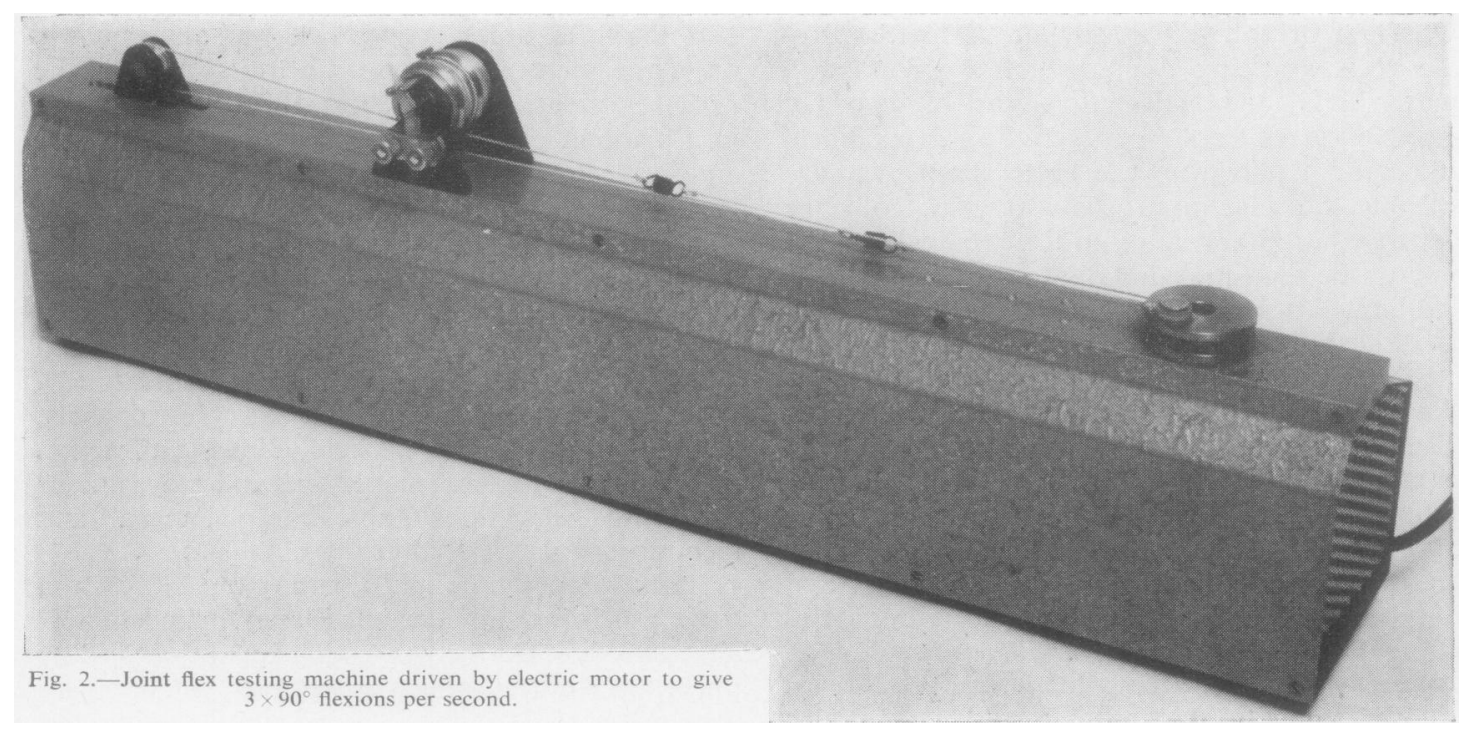


The powder, and the finished hardened material, is chemically akin to "Perspex" and has been shown to be fully compatible with living tissue. The liquid, however, prior to hardening (by polymerization), is an inflammable and powerful solvent and must not be allowed to be absorbed by the body or come into contact with sensitive tissues.

On addition of the liquid to the powder, a peroxide in the powder sets off a chemical reaction so that a large number of molecules join together to produce long chains. The liquid is thereby converted to a solid in which the undissolved particles of the powder remain embedded, the whole now being almost homogeneous chemically. Because the peroxide is not heat stable and is destroyed by heat sterilization, it is sterilized by gamma-irradiation and the liquid by filtration. During the hardening (polymerization), considerable heat is given off, but in the quantities and sites of application used by us this did not present a problem.

By employing methyl-methacrylate as a cement, it is possible to produce a perfect and rigid, but non-adhesive, fit for the stem of the prosthesis in bone. In order to prevent any movement of the stem which might take place in the longitudinal axis of the bones, the stem may be perforated, serrated, or notched, so that it is locked by the resin. One possible disadvantage of this method of fixation is

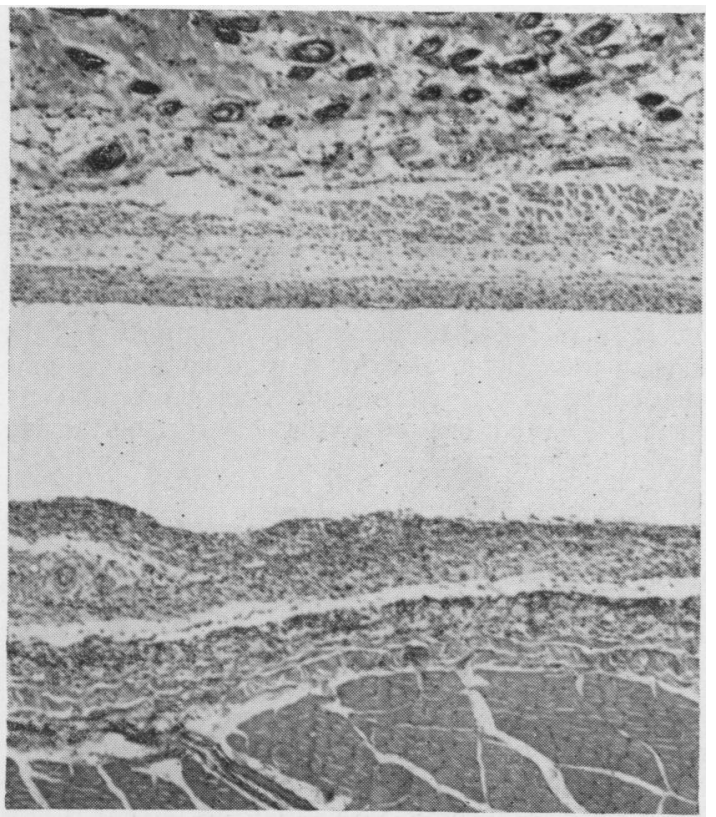

Fig. 3.-Microscopic appearance at 1 week of acrylic resin sheet implanted subcutaneously in the rat. Note cellular reaction (fibroblasts) around implant. Haematoxylin and eosin. $\times 40$. that removal of the prosthesis later, should this be necessary, might be difficult. It may well be found unnecessary (by experience) to provide such rigid fixation for the long axis of the stem, since the development of a new capsule some weeks after arthroplasty appears to limit distraction of the joint in its longitudinal axis.

\section{(4) Tissue Acceptability of Materials}

In order to study tissue reaction to polypropylene and methylmethacrylate, flat sheets of the materials were implanted into the anterior abdominal wall of rats, between the skin and the deep fascia overlying the abdominal musculature. The rats were killed after 1, 3, 5, and 12 weeks, and sections were prepared en bloc and stained in the usual way. At one week a vigorous vascular fibroblastic reaction was seen (Fig. 3), but by 5 weeks both implants were surrounded by an avascular envelope of mature fibrous tissue; at this stage no foreign body reactive giant cells or collections of lymphocytes were seen. At 12 weeks (Fig. 4), there was no material change compared with that seen at 5 weeks. From this it was concluded that both polypropylene and methylmethacrylate were well tolerated by the rat, having evoked no tissue reaction other than being sealed off by an envelope of collagen.

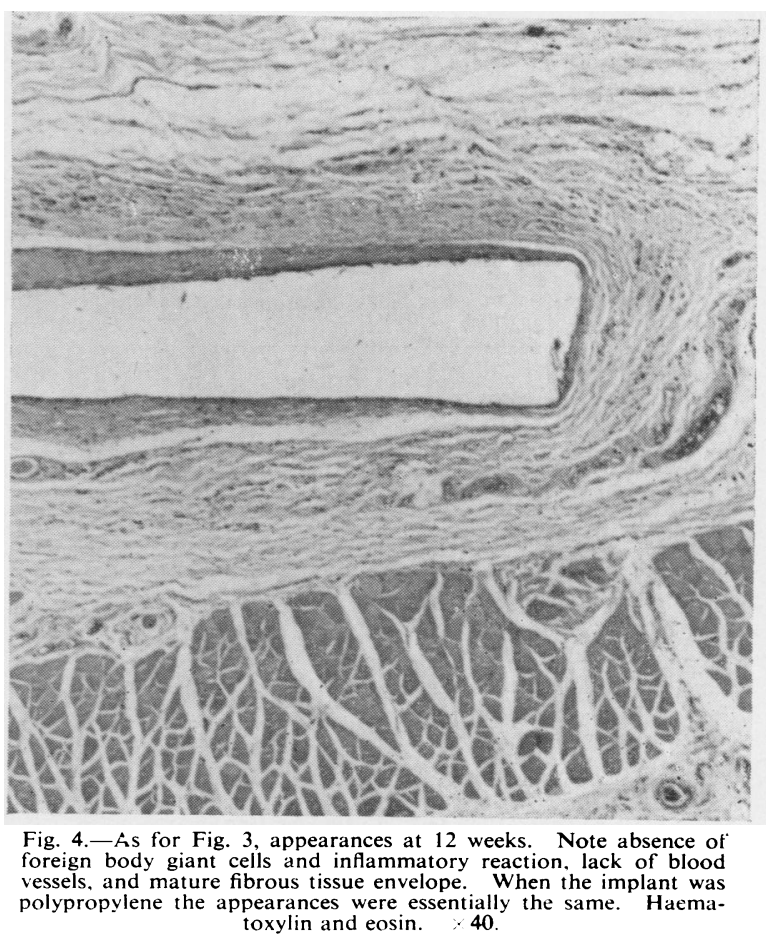




\section{(5) Methods of Sectioning Bone}

We wished to ensure that when the joint was excised, section of the shafts of the metatarsals and phalanges was clean and precise. If such a request is made to an engineer his answer, based on experience and general principles, is simple. He has a rigid saw to which he advances the bone on a moving platform with a precise and invariable angle between them. Because we felt the bone should be cut at $90^{\circ}$ to its long axis, and so allow a snug fit of the shoulder of a prosthesis to bone, a machine with a vibrating saw was designed and used in a pilot experiment. This method of sectioning bone demanded a lateral approach, whereas anatomical structures (digital nerves and vessels) indicated a dorsal one. The method was therefore abandoned in favour of a diamond-covered disc, held in a dental handpiece with an attached water jet for cooling the operative area, powered by a Kavo engine at 30,000 revolutions per minute. With practice, it was possible to divide bone fairly accurately at right-angles to its length, and without the fear of damage to neighbouring structures.

\section{Materials}

Eighteen artificial joints of various designs were used to replace the metatarso-phalangeal joints of six adult female greyhounds, of mean weight $50 \mathrm{lb}$. These were observed for 4-6 months and then killed. Ten were of conventional and eight of integral hinge design (Table).

TABLE

DETAIL OF EIGHTEEN PROSTHETIC JOINTS IN THE HIND PAWS OF SIX FEMALE GREYHOUNDS

\begin{tabular}{|c|c|c|c|c|}
\hline $\begin{array}{l}\text { Dog } \\
\text { No. }\end{array}$ & $\begin{array}{l}\text { Weight } \\
\text { (lb.) }\end{array}$ & $\begin{array}{c}\text { Paw and } \\
\text { MTP Joint }\end{array}$ & Type of Prosthesis & $\begin{array}{c}\text { Duration of } \\
\text { Observation } \\
\text { (wks.) }\end{array}$ \\
\hline \multirow[t]{2}{*}{$C / 677$} & \multirow[t]{2}{*}{49} & $\begin{array}{ll}\mathbf{R} & \mathbf{I I} \\
\mathbf{I V}\end{array}$ & $\begin{array}{l}\text { Hinge } 1 \\
\text { Hinge } 1 \text { (cement) }\end{array}$ & $\begin{array}{l}14 \\
10\end{array}$ \\
\hline & & L II & $\begin{array}{l}\text { Hinge } 1 \\
\text { Integral (cement) }\end{array}$ & $\begin{array}{r}13 \\
4\end{array}$ \\
\hline $\mathrm{C} / 720$ & 48 & L II & $\begin{array}{l}\text { Hinge } 1 \\
\text { Hinge } 1\end{array}$ & $\begin{array}{l}6 \\
6\end{array}$ \\
\hline \multirow[t]{2}{*}{$\mathrm{C} / 721$} & \multirow[t]{2}{*}{55} & $\mathbf{R} \quad$ II & $\begin{array}{l}\text { Hinge } 2 \\
\text { Integral (cement) }\end{array}$ & $\begin{array}{l}21 \\
18\end{array}$ \\
\hline & & L II & $\begin{array}{l}\text { Hinge } 2 \text { (cement) } \\
\text { Integral (cement) }\end{array}$ & $\begin{array}{r}19 \\
9\end{array}$ \\
\hline \multirow[t]{2}{*}{$C / 749$} & \multirow[t]{2}{*}{52} & $\mathbf{R} \quad$ II & $\begin{array}{l}\text { Hinge } 2 \text { (cement) } \\
\text { Integral (cement) }\end{array}$ & $\begin{array}{l}23 \\
17\end{array}$ \\
\hline & & L II & $\begin{array}{l}\text { Hinge } 3 \text { (cement) } \\
\text { Integral (cement) }\end{array}$ & $\begin{array}{l}22 \\
12\end{array}$ \\
\hline $\mathrm{C} / 280$ & 50 & R II & $\begin{array}{l}\text { Hinge } 4 \text { (cement) } \\
\text { Integral (cement) }\end{array}$ & $\begin{array}{l}22 \\
18\end{array}$ \\
\hline $\mathrm{C} / 832$ & 52 & $\mathbf{R} \quad$ III & $\begin{array}{l}\text { Integral (cement) } \\
\text { Integral (cement) }\end{array}$ & $\begin{array}{l}19 \\
15\end{array}$ \\
\hline
\end{tabular}

The prosthetic joints were invariably used to replace the metatarso-phalangeal joints of digits 2 and 3 because these are the main weight-bearing digits of the dog paw and the bone shafts are always larger than in digits 1 and 4.

\section{Methods \\ (1) Technique of Operation}

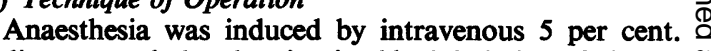
sodium pentothal and maintained by inhalation of nitrous oxide and oxygen with further small supplements of pentothal.

The hair of the hind paw was clipped closely and washed with soap and water followed by 1 per cent. $\stackrel{\circ}{\circ}$ "Hibitane" (Chlorhexidine) in spirit. A longitudinal incision of the skin over the metatarso-phalangeal joint $\bar{\alpha}$ (Fig. 5, opposite) exposed the long extensor tendon which was split and the two halves retracted laterally. The $i$ joint capsule was incised, the collateral ligaments were ${ }^{\circ}$ divided, and the bone ends cleared for about $1 \mathrm{~cm}$.

The thick sesamoids and flexor tendons beneath were $ᄋ$

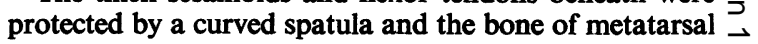
and phalanx sectioned by a diamond disc so that the total $\bar{z}$ bone removed was equal to that of the hinge area to be inserted. If the bone was sectioned at its neck the marrow cavity was easily seen and entered. In all instances $\mathscr{\odot}$ the cavity in the shaft of the bone was reamed to a $\odot$ suitable size and shape, using rose-head and fissure burrs held in the dental handpiece.

A metal template of the same size as the shaft of the prosthesis was then tried in the marrow cavity and any adjustments made until it was a good fit. The plastic joint was then inserted and examined for fit and mobility. If the stem of the prosthesis was found to be too long $\overrightarrow{\vec{O}}$ this was shortened with a knife. When methylmethacrylate was used as a cement for the prosthesis, retaining notches in the stem of the prosthesis were cut with a scalpel before it was mixed.

When the artificial joint had been inserted with $\frac{2}{2}$ satisfactory alignment and unimpeded movement, and $\frac{2}{\sigma}$ any excess cement had been removed, the split extensor 3 tendon was repaired with interrupted $5 / 0$ silk sutures and the skin closed by a subcuticular suture. A light dressing was held in place by a bandage and the paw immobilized in a position of rest by a plaster of Paris $\frac{5}{5}$ splint. The splint was removed at 2 weeks and the $\operatorname{dog} \frac{D}{O}$ allowed free movement.

\section{(2) Clinical Assessment}

All the dogs were assessed at weekly intervals for movement at the operative site, tenderness, and position $O$ of the paw on standing and on walking. Some were $\omega$ assessed on open ground when running.

\section{(3) Radiological Assessment}

$X$-ray films of both hindpaws were taken at variable intervals after operation, and such $x$ rays were repeated ? on the dissected and cleaned specimens post mortem. The post mortem $x$ rays taken in air and in water, and $\underset{\mathbb{D}}{\stackrel{O}{0}}$

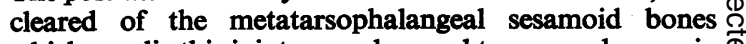
which overlie this joint were also used to assess changes in $\stackrel{\otimes}{\varnothing}$ bone density by Dr. F. Doyle. 

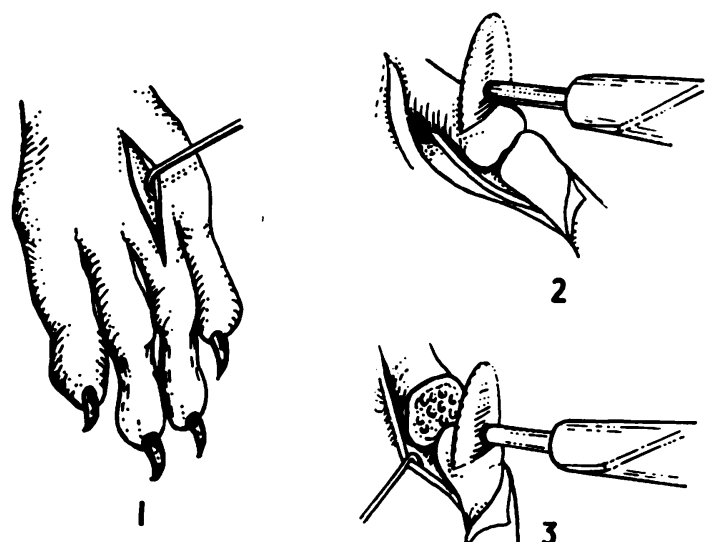

2
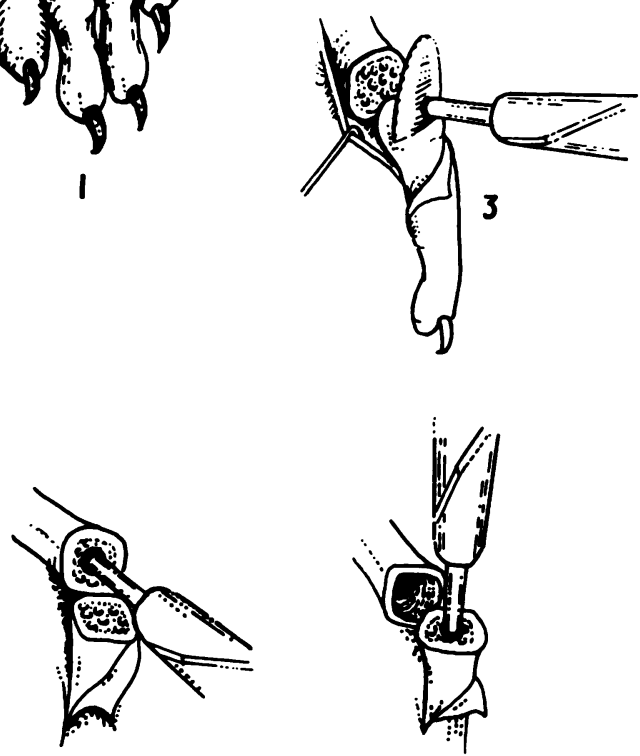

4
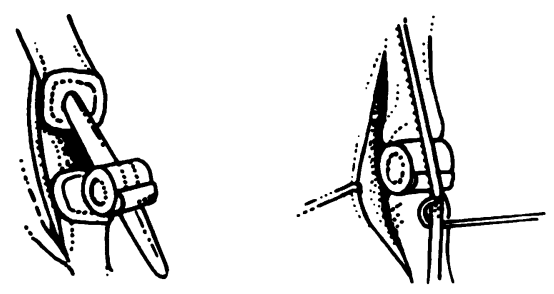

6

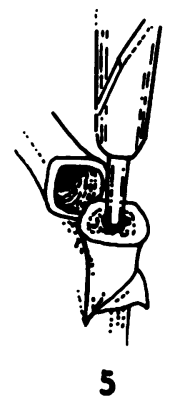

7

Fig. 5.-Diagram to illustrate surgical technique of joint replacement in the dog. In this the artificial joint used was one of the early prototypes.

\section{(4) Post mortem Assessment}

All joints were dissected post mortem and the covering soft tissues examined by the naked eye. The prostheses were then removed and examined with a hand lens for wear. The relevant bones were placed in buffered phosphate solution for bone density studies and later transferred to 15 per cent. formol-saline solution for histological examination. All bones were decalcified by

a formic citrate solution equivalent to 15 per cent. formic acid and sections 5 microns thick were cut by a sledge dermatome at sites dictated by changes in the $x$-ray films taken previously. These sections were stained by haematoxylin and eosin, and Van Gieson's stain.

\section{Results}

\section{Fixation}

Only five joints were inserted without cement fixation. It was clear that discomfort in the recently treated paw was considerably less when the prosthetic joint had been cemented into bone: many dogs were prepared to walk normally on the treated limb at one week when cement was used, whereas few did so even after 3 weeks without it. For this reason cement was used to fix the majority of joints irrespective of design.

At an early stage, 10 per cent. barium powder was incorporated into the polypropylene before processing, with the intention that this would make the joint radio-opaque. The barium was not evenly distributed and we also learned that the tensile strength of the polypropylene shafts was thereby considerably reduced. From being a rather tough and resilient material it became brittle and fragile. The procedure was therefore abandoned.

\section{Naked Eye Assessment}

At each review the artificial joint was put through a full range of movement passively and the dog was also observed walking and running. Slight residual swelling of the operation site was common at 3 months. Some reduction of movement at the site of the prosthetic joint particularly in (plantar) flexion was usual but less with the integral hinge joints. It was clear on post mortem examination that this reduction was due mainly to abuttal of plantar bone edges where this portion of bone had not been trimmed at the time of replacement. Alignment of the toes was usually good, but in seven instances there was rotation of the phalanx. At post mortem examination this was found to be due to:

(a) Rotation of shafts where cement was not used (3);

(b) Poor alignment of the prosthesis at the time of insertion (2);

(c) Unsuccessful cementing technique (2).

No prosthesis was broken, and a strong fibrous capsule, with a glistening lining, was invariably found enveloping the new joint. 


\section{Radiographic Control}

Some of the $x$ rays taken at follow-up are shown in Figs. 6 and 7, which make it clear that the periosteal and endosteal reaction varies greatly.
Where the reaction was greatest there had usually been perforation of the cortex during the reaming out or else the resultant rather thin cortex of the phalanx had been fractured during insertion of the $\stackrel{\vec{S}}{\rightarrow}$ prosthesis (Fig. 6). There were always changes in

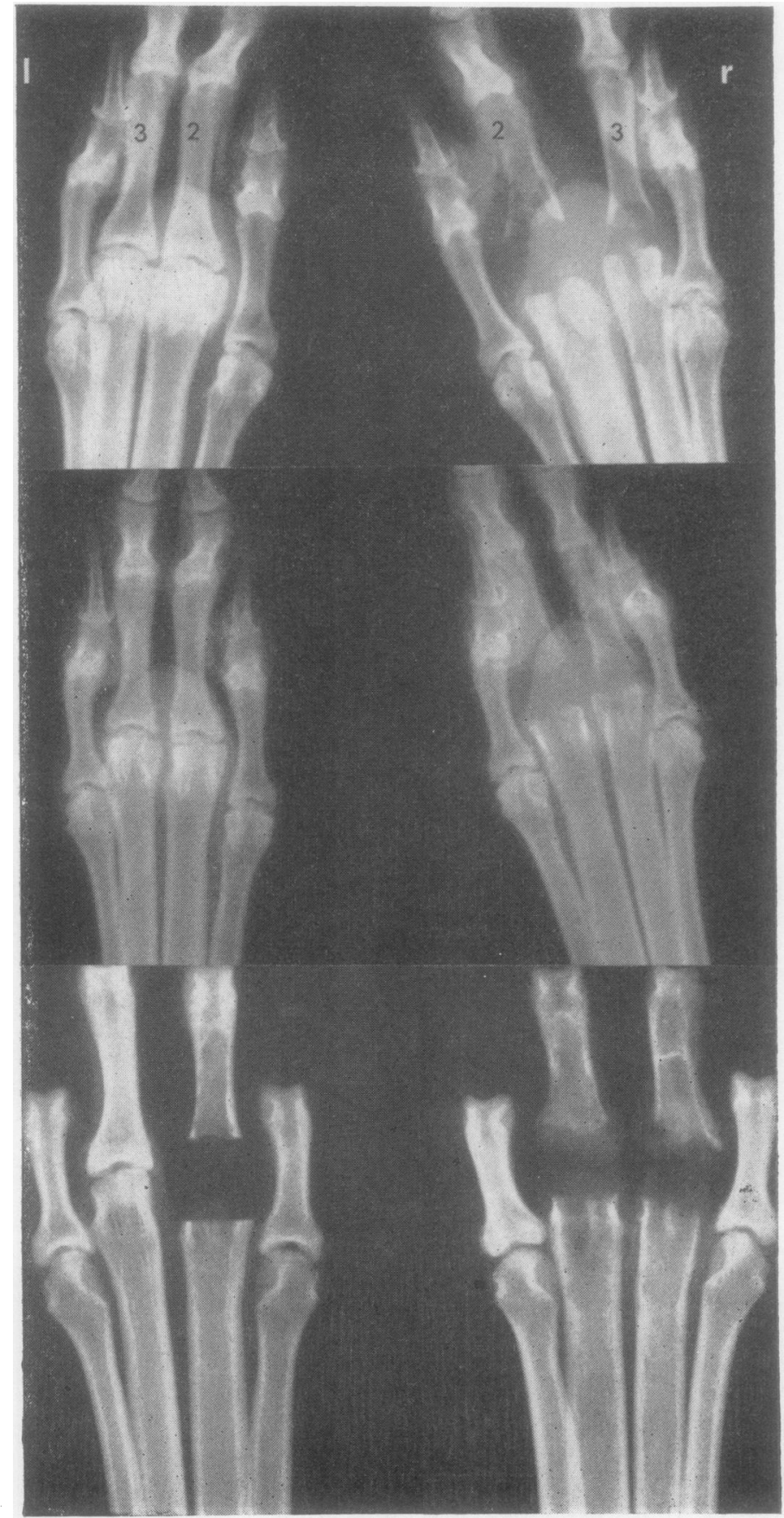

Fig. 6A. $-X$ ray of both hindpaws, $\operatorname{dog} C / 280$.

$R$. digit 2-Integral hinge joint at 1 month.

(Note fractured phalanx.)

$R$. digit 3-Integral hinge joint at 1 day.

Fig. 6B.-2 months later: the phalanx of digit $2 \mathrm{R} \stackrel{\mathrm{\alpha}}{\mathrm{a}}$ is healing satisfactorily.

Fig. 6C.-3 months later post mortem. There is still a little periosteal thickening around the metatarsal and phalanx of $\mathbf{R}$. digit 2 . The $\mathbf{L}$. digit 2 meta-O tarso-phalangeal joint was resected at this time for $(D$ comparison with the R. paw. Because all soft tissues $\Omega$ and sesamoid bones have been removed it is now easier to observe bony changes at the sites of joint 0 replacement. 
the periosteum and cortex close to the operative site and often evidence of osteoporosis or osteosclerosis in the shaft of the bone at a distance (Fig. 7). Because all these settled down and often returned to normal, we interpreted them as the natural reaction to trauma, and unrelated to the materials used.

Bone density studies seemed to confirm these naked eye observations for osteoporosis was common at 1 month but unusual after 3 months.

Fig. 7A. $-X$ ray of both hindpaws, $\operatorname{dog} C / 832$. $R$. digit 2-Integral hinge joint at 1 month. $R$. digit 3-Integral hinge joint at 1 day.

Fig. 7B. -2 months later.

Fig. 7C. -2 months later post mortem: note minimal bony changes and reversal of osteoporosis of metatarsals 2 and 3 seen in Fig. 7.B.

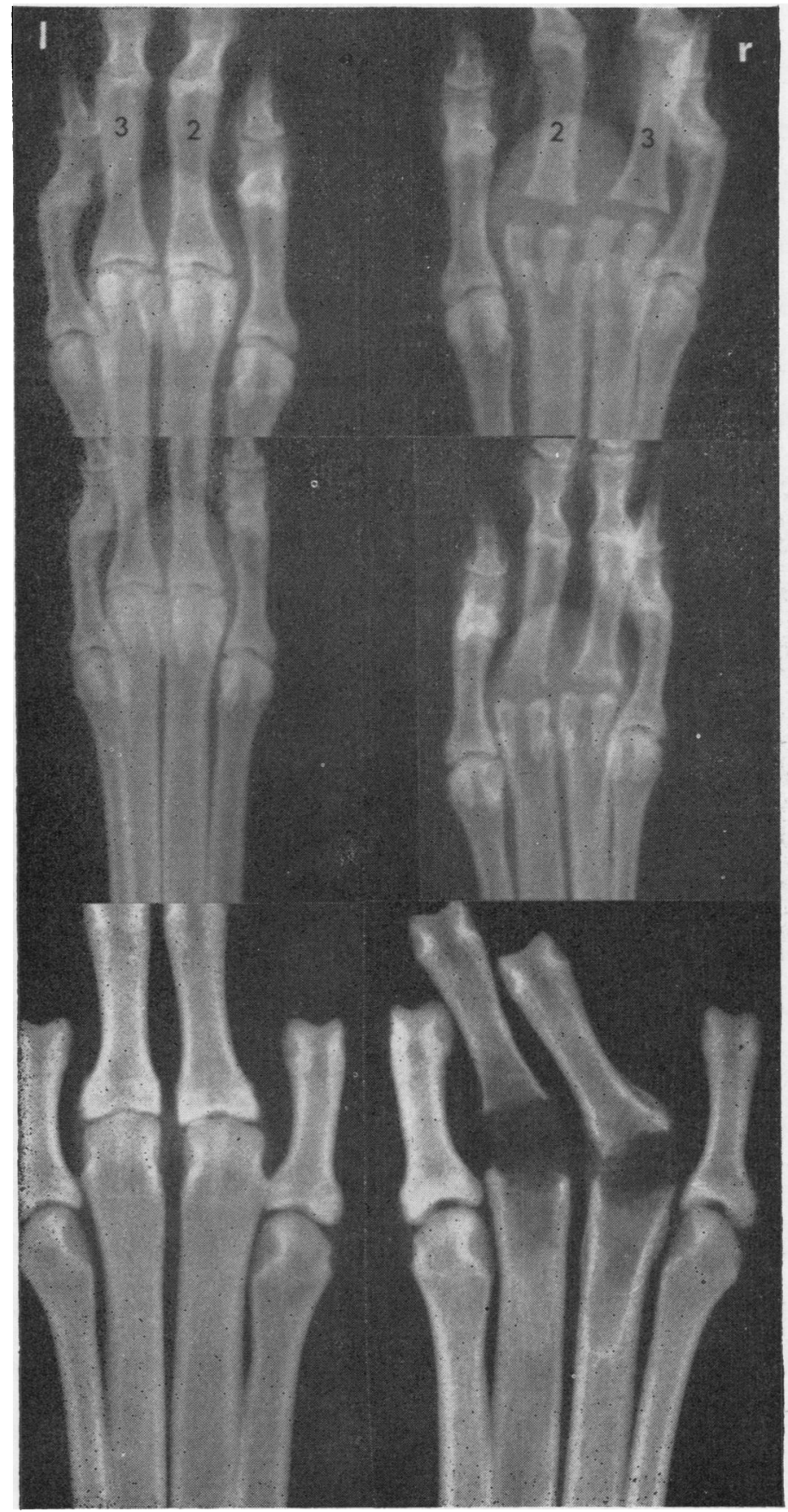




\section{Histology}

Histological study of bone was complicated by the difficulty of removing all the acrylic cement before the bone was processed. Since the cement was very much harder than the decalcified bone most sections were broken during cutting. They do however confirm the general pattern of events during healing of the bone (Fig. 8).

\section{Healing}

Although the skin wounds broke down and exposed the joint in two cases, infection was not a problem, and both healed without the need of secondary suture. As might be expected the amount of movement in both was small and the scar tissue on the dorsum of the joint was found to be thick and hard post mortem.

\section{Discussion}

It should be evident from the foregoing experiments and observations that replacement of small joints by a plastic artificial substance is both feasible

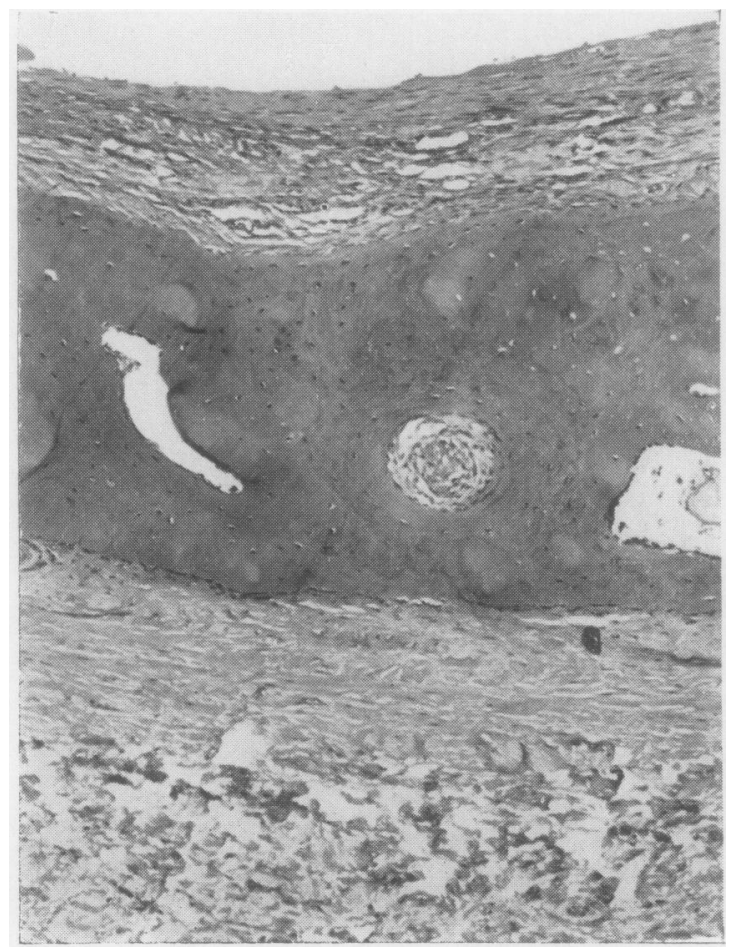
Fig. 8.A.-Microscopic appearances of bone. Haematoxylin and

[Note the normal-looking and living bone: the lacunae contain normal osteocytes. The endosteal fibrosis (above) lying in contact with the acrylic resin and polypropylene joint shows the same mature wibrous tissue as in Fig. 5. The periosteum (below) is a little thickened but shows no cellular infiltration. and practicable. It is clear too that firm anchorage of the artificial joint is a vital factor largely deter- $\frac{0}{\omega}$. mining the subsequent changes in the bone and periosteum.

It was noticeable that the reaction in bone was 0 slight, when fixation was perfect, moderate, when 들 fixation had been imperfect, and considerable, when $\frac{\overline{\bar{s}}}{\overline{\frac{1}{2}}}$ bone had been splintered or perforated at the time $\stackrel{\mathbb{\alpha}}{\circ}$ of insertion of the prosthesis.

The integral hinge would seem to be an advance over conventional designs, and in our hands has. been successful in the dog. There have been no $\overrightarrow{\vec{\omega}}$ mechanical failures in the joint but it may be advisable to immobilize the joint until a new capsule $\frac{0}{0}$ has formed around it and thus limit any lateral $\stackrel{\circ}{\mathrm{N}}$ strain, for in this direction the prosthesis may not be. as strong as the simple flexion tests have indicated.

In orthopaedic practice, plastic polymers have ? fallen into disfavour because of their mechanicalo failure under stress, in spite of their good tissue? tolerance (Cohen, 1967). Small particles of plastic $\bar{z}$ shed by wear from the main mass of material can form a "sludge" which is irritating to tissues

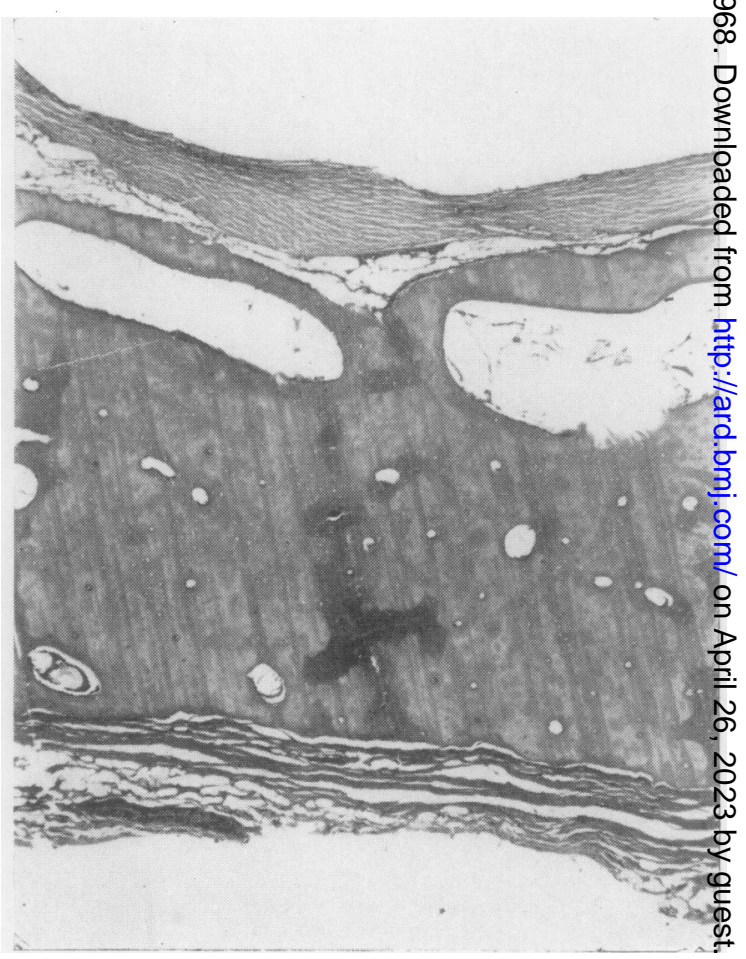

Fig. 8.B.-Microscopic appearance of bone. Haematoxylin and Dog $\mathrm{C} / 832$. $R$, digit 2 metatarsal at 19 weeks.

[The endosteal layer (above) is very mature fibrous tissue, and the periosteal layer (below) quite thin. The bone is rather hyaline and has several vascular spaces lined by endothelium, with a population of osteocytes.] 
(Charnley, 1966). We believe the polypropylene is well able to stand up to the stresses of normal function in a hand, as opposed to those of a weightbearing joint. Certainly in the dog the metatarsophalangeal joints do bear weight, and there was no evidence of wear although the period of observation was perhaps too short. The integral hinge with its absence of "moving parts" should not produce any sludge.

From these reassuring experimental observations it would seem reasonable to plan and carry out a clinical trial in humans, using polypropylene integral hinge joints with methylmethacrylate cement fixation.

\section{Summary and Conclusions}

(1) The need for a replacement for joints of the hand in rheumatoid arthritis and the requirements of such a joint are discussed.

(2) The stages in the development of a suitable joint, the methods of sectioning bone and of fixation of the joint, and the tissue acceptability of the materials used are described.

(3) Eighteen artificial joints replaced the natural metatarso-phalangeal joints in a series of six dogs, and these were observed for periods up to 6 months.

(4) All joints were assessed by function, by serial radiography, by naked eye dissection post mortem, and by histological changes in bone.

(5) The results of this experimental study indicate that a clinical assessment of similar joints in humans would be justified.

It is a pleasure to acknowledge the assistance provided by Mr. L. M. Taylor (technical), Mr. R. Reid (engineering), Miss S. Barker (medical artist), and Mrs. J. Mepham (histology).

The work was supported by a generous grant from the Arthritis and Rheumatism Council for Research.

\section{REFERENCES}

Bäckdahl, M. (1966). In "Modern Trends in Plastic Surgery", series 2, ed. T. Gibson, p. 195. Butterworths, London.

Brannon, E. W., and Klein, G. (1959). J. Bone Jt Surg., 41A, 87 (Experiences with a finger-joint prosthesis).

Charnley, J. (1960). Ibid., 42B, 28 (Anchorage of the femoral head prosthesis to the shaft of the femur). (1966). Personal communication.

Cohen, J. (1967). Amer. J. Surg., 114, 31 (Biomaterials in orthopedic surgery).

Estevez, J. M. J. (1966). Personal communication.

Flatt, A. E. (1961). J. Bone Jt Surg., 43A, 753 (Restoration of rheumatoid finger-joint function). (1963). "The Care of the Rheumatoid Hand." Mosby, St. Louis.

Fowler, S. B., and Riordan, D. C. (1958). J. Bone Jt Surg., 40A, 1431 (Surgical treatment of rheumatoid deformities of the hand).

London Splint Co. Catalog (1964). Bateman finger-joint prosthesis, illustr. No. 6317, p. 54. Street finger-joints, illustr. No. 6441, p. 53. Thompson mechanical finger-joint, illustr. No. 6948, p. 54.

McKee, G. K. (1966). Personal communication.

- and Watson-Farrar, J. (1966). J. Bone Jt Surg., 48B, 245 (Replacement of arthritic hips by the McKee-Farrar prosthesis).

Smith, R. J., and Kaplan, E. B. (1967). Ibid., 49A, 31 (Rheumatoid deformities at the metacarpophalangeal joints of the fingers).

Vainio, K. (1967). "Modern Trends in Orthopaedics", 5th series, ed. W. D. Graham. Butterworths, London. 


\section{Prosthèses articulaires des doigts dans la polyarthrite rhumatoide}

\section{RÉSUMÉ}

(1) On discute la question du remplacement des articulations de la main au cours de la polyarthrite rhumatoïde et les conditions requises pour cela.

(2) On décrit les étapes menant à la construction d'une articulation adéquate, les méthodes de resection osseuse et de fixation de l'articulation ainsi que la tolérance tissulaire du matériel utilisé.

(3) On a remplacé 18 articulations métatarsophalangiennes par des articulations artificielles chez six chiens et on les a observé pendant plus de six mois.

(4) On a évalué la qualité de ces articulations par l'étude de la fonction, des radiographies répétées et, après le sacrifice des animaux, par l'examen macroscopique à la dissection et microscopique des altérations osseuses.

(5) Les résultats de cette étude expérimentale indiquent qu'il serait justifié de tenter d'évaluer cliniquement de telles articulations chez l'homme.
Articulaciones artificiales de los dedos en la poliartritis reumatoide

Sumario

(1) Se discute el problema de reemplazo de articulaciones de la mano en el curso de la poliartritis reumatoide? y los requisitos de tales articulaciones.

(2) Se describen las etapas en la construcción de una articulación adecuada, los métodos de resección ósea y de fixación de la articulación así como la acceptabilidade tisular de los materiales usados.

(3) Se han substituido 18 articulaciones metatarsofalangianas por articulaciones artificiales en seis perros $\overrightarrow{0}$ que luego fueron observados durante más de seis meses.

(4) Se apreció la cualidad de estas articulaciones por $\vec{\omega}$ el estudio de la función, radiografías repetidas y, despuéso del sacrificio de los animales, por el examen macroscópico a la disección y microscópico de las alteraciones óseas.

(5) Los resultados de este estudio experimental indican $N$ que una apreciación clínica de tales articulaciones en el $\mathrm{j}_{\omega}$ hombre se ve justificada. 